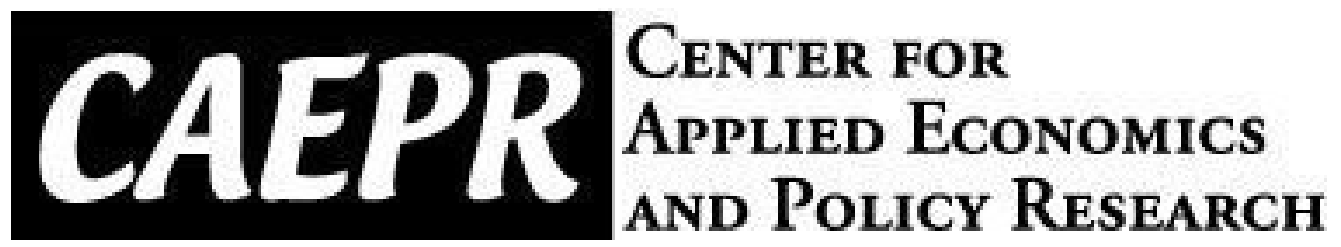

\author{
CAEPR \\ Working Paper \\ \#2017-015
}

Price Search, Consumption Inequality, and Expenditure
Inequality over the Life Cycle

Yavuz Arslan

Bank for International Settlements (BIS)

Bulent Guler

Indiana University Bloomington - Department of Economics

Temel Taskin

World Bank

August, 2016

This paper can be downloaded without charge from the Social Science Research Network electronic library at https://papers.ssrn.com/abstract_id=3080418

The Center for Applied Economics and Policy Research resides in the Department of Economics at Indiana University Bloomington. CAEPR can be found on the Internet at: http://www.indiana.edu/ caepr. CAEPR can be reached via email at caepr@indiana.edu or via phone at 812-855-4050.

(C)2017 by Yauuz Arslan, Bulent Guler and Temel Taskin. All rights reserved. Short sections of text, not to exceed two paragraphs, may be quoted without explicit permission provided that full credit, including (C) notice, is given to the source. 


\title{
Price Search, Consumption Inequality, and Expenditure Inequality over the Life Cycle*
}

\author{
Yavuz Arslan ${ }^{\dagger} \quad$ Bulent Guler ${ }^{\ddagger} \quad$ Temel Taskin ${ }^{\S}$
}

August 2016

\begin{abstract}
In this paper, we incorporate price search decision into an otherwise standard life-cycle model with incomplete markets and an endogenous labor supply, differentiating consumption from expenditure. In our model, consumers can allocate part of their time to searching for low prices, and this leads to an endogenous price dispersion. We have three contributions. First, we analytically study the determinants of price search and its relation to consumption and expenditure inequalities in a static model. Second, we study quantitatively the role of price search in a dynamic version of the model. A plausible calibration implies that the life-cycle increase in the cross-sectional variance of log consumption is about 40 percent lower than the increase in the cross-sectional variance of log expenditure. Third, we show that price search provides an additional quantitatively significant partial insurance mechanism against adverse income shocks.
\end{abstract}

Keywords: Consumption inequality, price search, incomplete markets, life cycle models, partial insurance.

J.E.L. Classification: D10, D91, E21.

${ }^{*}$ We would like to thank Mark Aguiar, Mark Bils, Árpád Ábrahám, Yongsung Chang, Fatih Guvenen, Tarık Kara, Fatih Karahan, Burhanettin Kuruscu, Serdar Ozkan, Fabrizio Perri, Christian Upper, seminar participants at the University of Rochester, the European University Institute, the Central Bank of the Republic of Turkey, the Midwest Macro Meeting in Bloomington, Indiana, the Society for Economic Dynamics Meeting in Istanbul, the Royal Economic Society Meeting in London and the Latin American Meeting of the Econometric Society in Santiago, Chile. All errors are our own; comments are very welcome. The views expressed here are those of the authors and do not reflect those of the World Bank or the Bank for International Settlements.

${ }^{\dagger}$ Bank for International Settlements. Email: yavuz.arslan@bis.org

‡Indiana University. Email: bguler@indiana.edu

§World Bank. Email: ttaskin@worldbank.org 


\section{Introduction}

Most of the extant studies of life cycle profile of consumption inequality implicitly assume that consumption and expenditure are equivalent. ${ }^{1}$ However, another strand in the literature has documented significant dispersion in prices paid for identical goods, which implies a difference between consumption and expenditure. ${ }^{2}$ If the documented price dispersion is not random across population, then an assumption that consumption and expenditure are equivalent may have important implications for inequality. ${ }^{3}$ In this paper we relax this assumption and find that the rise in consumption inequality over the life cycle is potentially much lower than the rise in expenditure inequality.

We first analyze the determinants of price search decision in a simplified static model. We show analytically that when labor supply is zero, price search is a decreasing function of wealth. However, when labor supply is endogenous, price search becomes independent of wealth and negatively correlated with wage. We then analyze the effect of price search on expenditure inequality and consumption inequality. We show analytically that expenditure inequality is larger than consumption inequality. In the case of endogenous labor supply, this gap crucially depends on the covariance of consumption and wage. Given that empirically motivated quantitative lifecycle models generate a positive covariance between consumption and wage, we can show that expenditure inequality is higher than consumption inequality when labor supply is endogenous.

To quantify the significance of price search, we use a standard life-cycle model with incomplete markets and endogenous labor supply. We assume that individuals face idiosyncratic income shocks. They can insure themselves against these shocks through a risk-free asset and a flexible labor supply. Contrary to the standard models, we also allow agents to search for cheaper prices to offset the effects of adverse shocks. When agents search more intensely for cheaper prices, they pay less and consume more, and they also enjoy less leisure due to time constraints. Optimality implies that in equilibrium the marginal return and cost of price search should be equalized. The marginal return to price search comes from additional consumption, and is smaller for agents who already have high consumption. In equilibrium, agents with low wealth and bad income shocks

\footnotetext{
${ }^{1}$ A partial list of studies in this line of research includes Deaton and Paxson (1994), Blundell and Preston (1998), Gourinchas and Parker (2002), Storesletten et al. (2004), Guvenen (2007), Blundell et al. (2008), Kaplan and Violante (2010), Heathcote et al. (2014), and Aguiar and Bils (forthcoming).

${ }^{2}$ Baye et al. (2006) provide a detailed survey of the dispersion in prices paid for identical goods. Aguiar and Hurst (2007) show that, in the US richer people pay higher prices for identical goods. Also, they report that prices paid for identical goods change over the life cycle, and that this is a result of a change in price search due to a change in the cost of time. Similar results are also shown by Kaplan and Menzio (forthcoming). Using the US data, Sorensen (2000) reports a significant dispersion in prices paid for the same medicine. Dahlbay and West (1986) show that there is substantial price dispersion among automobile insurance companies in Canada. Pratt et al. (1979) document price dispersion for several categories of goods. Kaplan and Menzio (forthcoming) show that the existence of price search can result in self-fulfilling unemployment fluctuations.

${ }^{3}$ This concern is also recently mentioned in Attanasio and Pistaferri (2016).
} 
tend to search more and pay less. We next calibrate our model, and quantify the magnitude of this gap for the US economy. Our results show that the life-cycle increase in the variance of consumption is roughly $11 \log$ points (40 percent of expenditure inequality) smaller than the life-cycle increase in the variance of expenditure.

In addition to its impact on consumption levels, price search enables consumers to insure themselves against idiosyncratic income shocks. Following the formulation of Blundell et al. (2008) and Kaplan and Violante (2010), we quantify the partial insurance role of price search by computing the consumption insurance coefficients with respect to transitory and persistent shocks. The computed insurance coefficient of consumption for persistent shocks is $8 \%$ higher in the model with price search compared to the one with no price search. The same coefficient is $15 \%$ higher for transitory shocks.

Among the many studies in the quantitative life-cycle literature, this paper is most closely related to Guvenen (2007), Storesletten et al. (2004), and Karahan and Ozkan (2010). Those papers study the role of income processes in the age-inequality profile of consumption. Kaplan (2012) extends a similar model with unemployment risk to better match age-inequality profiles of consumption and labor allocations over the life cycle. There is a common implicit assumption in those models that the price of a consumption good is unique, and that consumption therefore is equal to expenditure. Our paper differs from standard life-cycle studies in that it differentiates consumption from expenditure. We show that this distinction plays a quantitatively significant role in the age-inequality profile of consumption.

The paper continues as follows. In section 2, we study a simple static model from which we drive some theoretical results. In section 3, we present a dynamic model, and in section 4, we explain the details of its calibration and report the results. We present conclusions in section 5.

\section{A static model of price search}

In the next section we present a quantitative model that shows dynamic consumption and saving choices, static labor supply, and price search decisions. But first, we focus on a static problem for insight into the quantitative results involved in closed form theoretical relationships. In the static problem, the individual chooses the optimal level of labor supply and price search given the current wealth and the next period saving choice.

\subsection{Static Problem}

The static problem can be summarized as the maximization of the periodic utility function given the state variables and the choice of next period saving. Denoting $w$ as the current period wage 
rate and $y$ as the current wealth net of saving, we can formulate the static problem as follows:

$$
\max _{c, s, n} u(c, 1-l)
$$

subject to

$$
p(s) c=w n+y
$$

and

$$
\alpha s c^{\psi}+n+l=1
$$

where $c$ is consumption, $s$ is price search, $\alpha$ is the parameter that translates price search into time cost, $l$ is leisure, $n$ is labor supply and $p(s)$ is the price paid. ${ }^{4}$ We assume that when an individual chooses price search, he assigns an amount of time, $\alpha$, for each unit of consumption. Then, total time cost becomes $\alpha s c^{\psi}{ }^{5}$

Positive Labor Supply: We first analyze the case in which the labor supply is positive, $n>0$. In this case, the following lemma characterizes the price search as a function of wage, consumption and wealth.

Lemma 1 When labor supply is endogenous and positive, the equation characterizing price search becomes:

$$
p^{\prime}(s)=-\alpha w c^{\psi-1}
$$

If we further assume that consumption is a normal good and price is a convex function of search, i.e., $p^{\prime \prime}(s)>0$, then we have

$$
\frac{d s}{d y} \begin{cases}<0 & \text { if } \psi<1 \\ =0 & \text { if } \psi=1 \\ >0 & \text { if } \psi>1\end{cases}
$$

When labor supply is positive, marginal value of leisure increases as wealth does, while the labor supply itself declines. As available time for search increases, the marginal cost of price search declines. This channel increases the incentive for price search. However, higher wealth increases consumption as well. Higher consumption makes each unit of extra price search more costly as total time spent on search will increase more with a larger consumption bundle. The magnitude of these two forces depend crucially on the curvature parameter for consumption in the time cost of price search, $\psi$. When $\psi=1$, these two forces cancel out each other, and price

\footnotetext{
${ }^{4}$ To be more precise, $s$ is the number of offers that a consumer chooses to receive. We assume that the price function, $p($.$) , is continuous and twice differentiable. Later, we specify the price function through micro-foundation, and it$ satisfies these assumptions.

${ }^{5}$ See the next section for a full description of the search process.
} 
search becomes independent of wealth. However, if $\psi<1$, then price search decreases as wealth increases, and if $\psi>1$, then price search becomes an increasing function of wealth.

The dataset regarding price search does not have information on wealth. Thus, we have no prior knowledge of what $\psi$ needs to be. However, in order to proceed with further analytical results, we restrict ourselves to the case $\psi=1$. Thus, we have the following assumption, which holds for the rest of this paper.

Assumption 1 The curvature parameter for consumption in the time cost of price search is equal to 1 , i.e. $\psi=1$.

Given this assumption, another immediate result following Lemma (1) is that as long as $p^{\prime \prime}(s)>$ 0 , price search decreases as wage increases. ${ }^{6}$

Corollary 1 Under Assumption 1, when labor supply is endogenous and positive and price is a convex function of search, i.e. $p^{\prime \prime}(s)>0$, price search decreases as wage increases. That is, $\frac{d s}{d w}<0$.

An increase in wage may cause an increase or decrease in the labor supply, depending on the magnitude of substitution and income effects. However, a higher wage unambiguously decreases price search. The intuition is that in this static model, absent any endogenous labor decision, wage and wealth change similarly. From the previous Lemma we know that, absent the wage affect, the marginal benefit and cost of higher consumption due to higher wealth cancel out each other. However, unlike in the previous lemma, as labor is endogenous, the marginal cost of search increases more (compared to the wealth effect) due to higher wages. As a result, extra time cost due to higher wages implies lower price search.

When labor supply is endogenous and positive, none of the results above depends on the functional forms of utility and price functions. These results are quite general. The only assumption generating these results is the way consumption effects the time cost of price search. In the robustness section, we do several analysis to determine the quantitative role of this modeling assumption.

In order to obtain further analytical results, we assume in this section the following simplified pricing technology: ${ }^{7}$

$$
\log (p)=\theta_{0}+\theta_{1} \log (s)
$$

We should note in the quantitative model we provide micro-foundation for the price technology, and the resulting price function implies a very similar functional form when the distribution of prices follows a normal distribution.

\footnotetext{
${ }^{6}$ The price function derived in equation (10) satisfies this condition as long as $s>1$.

${ }^{7}$ This is the same price function used in Aguiar and Hurst (2007).
} 
Given 5, we can express the price search explicitly as a function of wage:

$$
\log (s)=\frac{\theta_{0}+\log \left(\frac{-\theta_{1}}{\alpha}\right)}{1-\theta_{1}}-\frac{\log (w)}{1-\theta_{1}}
$$

Zero Labor Supply: Next, we analyze the case in which there is no labor supply, $n=0$. This corresponds to cases in which individuals have sufficiently large wealth and/or are retired. In such a case, we can solve for price search explicitly as a function of fundamental parameters of the model:

Lemma 2 Under Assumption 1, when labor supply is zero, price search can be expressed as the following:

$$
\log s=A-\frac{\sigma+\gamma}{(1+\gamma)-\theta_{1}(\sigma+\gamma)} \log (y),
$$

where $A=\frac{\theta_{0}(\sigma+\gamma)-\log \left(\alpha^{1+\gamma} \phi\left(1-\frac{1}{\theta_{1}}\right)\right)}{(1+\gamma)-\theta_{1}(\sigma+\gamma)}$.

Corollary 2 If labor supply is zero and the return to price search is positive, i.e. $\theta_{1}<0$, then price search is decreasing in wealth. That is, $\frac{d s}{d y}<0$.

This is an immediate result of equation (7) and the fact that $\theta_{1}<0$. Intuitively, it implies that, when labor supply is zero, price search decreases as wealth increases. There are two reasons driving this result. First, as wealth increases consumption increases, and this makes time involved in price search more costly. Second, increases in wealth tend to push upward the marginal value of leisure, which in turn decreases the price search. The combination of these two forces implies that price search decreases as wealth increases.

\subsection{Expenditure vs. Consumption Inequality}

Having derived optimality conditions for price search, we can now discuss the effects of price search on consumption and expenditure inequality. Our ultimate goal is to understand the effect of price search on the wedge between consumption and expenditure inequality. Since expenditure is equal to price times consumption, we can express the connection between expenditure and consumption inequality as follows:

$$
\operatorname{Var}(\log e)=\operatorname{Var}(\log c)+\operatorname{Var}(\log p)+2 \operatorname{Covar}(\log p, \log c)
$$

Thus, the difference between expenditure inequality and consumption inequality depends on the variance of log prices paid and the covariance of log prices and log consumption. We next analyze these terms in the case of exogenous labor supply and endogenous labor supply. 
Zero Labor Supply: In the case of zero labor supply, we can derive an analytical expression defining the relation between expenditure and consumption inequalities. Expenditure inequality, defined by the variance of log expenditures, becomes a constant proportion of consumption inequality, defined by the variance of log consumption. The following lemma summarizes the result:

Lemma 3 Under assumption 1, when labor supply is zero, the relation between the variance of log expenditures and the variance of log consumption is characterized by the following equation:

$$
\operatorname{Var}(\log e)=\left(1-\theta_{1} \frac{\sigma+\gamma}{1+\gamma}\right)^{2} \operatorname{Var}(\log c)
$$

Corollary 3 When labor supply is zero, the variance of log expenditures is higher than the variance of $\log$ consumption as long as $\theta_{1}<0$. That is, $\operatorname{Var}(\log e)>\operatorname{Var}(\log c)$.

The corollary is an immediate consequence of equation (8). From Lemma 2 we know that price search is a decreasing function of wealth. Therefore, wealthier (or, equally, high consumption) individuals pay higher prices compared to poorer ones. This mechanism renders the difference between expenditure levels larger compared to consumption, which makes the expenditure variance larger. It is also apparent from equation (8) that as risk aversion, $\sigma$, and the inverse of Frisch elasticity, $\gamma$, increase the gap between expenditure and consumption inequality widens. Moreover, as the return to price search increases, which is also to say as the absolute value of $\theta_{1}$ increases, again, the gap between expenditure and consumption inequality increases. We will return to these observations in Section 4.3, when we conduct several robustness analyses with respect to important parameters of the model.

\section{Endogenous Labor Supply:}

Lemma 4 Under Assumption 1, if labor supply is endogenous and positive, the relation between consumption and expenditure inequality is as follows:

$$
\operatorname{Var}(\log e)=\left(\frac{\theta_{1}}{1-\theta_{1}}\right)^{2} \operatorname{Var}(\log w)+\operatorname{Var}(\log c)-2 \frac{\theta_{1}}{1-\theta_{1}} \operatorname{Cov}(\log c, \log w)
$$

Lemma 4 has an implication for the life-cycle behavior of the relative sizes of expenditure and consumption inequalities. The statistical properties of the estimated income process imply that $\operatorname{Var}(\log w)$ is an increasing function over the life-cycle. Moreover, $\operatorname{Cov}(\log c, \log w)$ is positive and increasing over the life-cycle. So, by using the above equation, we can conclude that the difference between $\operatorname{Var}(\log e)$ and $\operatorname{Var}(\log c)$ is positive and increases over the life-cycle. 
Taking Stock: The static model presented in this section shows us that price search decreases as wealth increases when labor supply is zero. That is, wealthier individuals search less for attractive prices and pay more for the same consumption bundle. When labor supply is positive, we find that price search is independent of wealth but decreases with wage. This also implies that the gap between expenditure and consumption inequalities is mainly driven by the evolution of wage and the covariance of consumption and wages, both of which increase over the life-cycle in standard models. Therefore, in the next section we aim to quantify the difference between expenditure and consumption inequalities, using a standard life-cycle model augmented with labor supply and price search choices.

\section{Quantitative Model}

Our model is an extension of a standard life-cycle consumption-saving problem with an endogenous labor supply and a price search technology, allowing agents to search for cheaper prices and partially insure themselves against adverse income shocks. ${ }^{8}$ The asset markets are incomplete due to uninsurable idiosyncratic income shocks. The population consists of a continuum of agents who work for $T$ periods and afterwards enjoy retirement until period $T^{*}$. Retirement is imposed exogenously at period $T$. We study the age-inequality profiles of consumption and expenditure in this environment. Each component of the model is explained in detail below.

\subsection{Households}

In each period, agents make two decisions: one is the consumption/saving decision, and the other is the decision on time allocation between leisure, labor supply, and price search. Agents can enjoy more consumption by searching for lower prices; however, in that case they have less time for leisure and labor supply. They maximize the expected lifetime value of discounted utility:

$$
E \sum_{t=0}^{T^{*}} \beta^{t} u\left(c_{t}, l_{t}\right),
$$

where, $u(\cdot)$ is period utility, $\beta$ is the time discount factor, $c_{t}$ is consumption, and $l_{t}$ is the leisure time for the agent at period $t$. We use a utility function similar to Kaplan (2012) that is standard in the literature and is specified as follows:

$$
u\left(c_{t}, l_{t}\right)=\frac{c_{t}^{1-\sigma}}{1-\sigma}-\phi \frac{\left(1-l_{t}\right)^{1+\gamma}}{1+\gamma}
$$

\footnotetext{
${ }^{8}$ See Becker (1965) and Becker and Ghez (1975) for a benchmark theory of the role of time allocation over the life cycle.
} 


$$
p\left(s_{t}\right) c_{t}+a_{t+1}=w_{t} n_{t}+(1+r) a_{t}
$$

where $p(\cdot)$ is the price of the consumption good that depends on the individual search time for prices, $s_{t}$. Consumption and saving in the current period are denoted by $c_{t}$ and $a_{t+1}$, respectively. We denote the current wage with $w_{t}$ and follow the literature on the process governing the evolution of wages over the life-cycle. In each period, an individual receives both persistent and transitory labor income shocks. The log wage follows:

$$
\log \left(w_{t}\right)=\beta_{0}+\beta_{1} t+\beta_{2} t^{2}+z_{t}+\epsilon_{t}, \text { with } \epsilon_{t} \sim N\left(0, \sigma_{\epsilon}^{2}\right)
$$

where $\beta_{0}$ is a scale parameter, $\beta_{1}$ is the return to experience, $t$ is the number of years of experience, $z_{t}$ is the persistent wage shock, and $\epsilon_{t}$ the transitory wage shock. The persistent wage shocks follow an $A R(1)$ process:

$$
z_{t}=\rho z_{t-1}+v_{t} \text {, with } z_{0}=0 \text { and } v_{t} \sim N\left(0, \sigma_{v}^{2}\right)
$$

We also assume that households face a borrowing limit, which is a constant fraction $(\underline{a})$ of the natural borrowing limit in each period.

Price Search Technology: While there are several empirical studies that estimate effects of price search on prices paid, the extant literature provides limited guidance on how individuals search for prices in the market.

Following the seminal paper by Stigler (1961), we assume that individuals can affect the price they pay by spending more time on shopping. More specifically, we assume that the distribution of prices is given by an exogenous, commonly known, non-degenerate distribution $F(p)$ on $[\underline{p}, \overline{\bar{p}}]$. At the beginning of each period, individuals decide on the amount of time that they will devote to price search. Denoting $s$ as the amount of price search per unit of consumption (or variety), they receive price quotes from $s$ stores, and then pick the lowest price quote. That is, the price individuals pay upon receiving $s$ quotes is $\min \left\{p_{1}, p_{2}, \ldots, p_{s}\right\}$. It can be shown that the distribution of the lowest of $s$ draws is $F_{\min }(p ; s)=1-[1-F(p)]^{s}$. The expected price paid by the individual upon obtaining $s$ quotes becomes $E\left(p_{\min } ; s\right)=\int_{p}^{\bar{p}} p d F_{\min }(p ; s)=\underline{p}+\int_{p}^{\bar{p}}[1-F(p)]^{s} d p$, where the second equality is obtained from integration by parts. We assume that in a given period individuals pay the following price: ${ }^{9}$

$$
p(s)=E\left(p_{\min } ; s\right)=\underline{p}+\int_{\underline{p}}^{\bar{p}}[1-F(p)]^{s} d p .
$$

\footnotetext{
${ }^{9}$ This assumption can be supported by assuming that individuals repeat the process of obtaining a fixed amount of price quotes a sufficient number of times within a period. As long as each quote is independent from each other, individuals will pay this expected price within the period.
} 
It is easy to show that price search lowers the level of price paid, as indicated by the following Lemma. As the size of price quotes increases, the chance of receiving a lower price quote also increases:

Lemma 5 Price search lowers the price paid, i.e. $\frac{d p}{d s}<0$.

However, each quote is costly. Specifically we assume that it takes time effort to receive these quotes. An individual with one unit/variety of consumption who chooses to receive $s$ quotes needs to dedicate $\alpha_{t} s$ of her time in a period, where $\alpha_{t}$ is an age-dependent constant converting number of quotes into time cost. ${ }^{10}$ Extending this to an entire consumption basket, an individual with a consumption level of $c_{t}$ spends $\alpha_{t} s_{t} c_{t}$ of her time searching. Together with the time spent on working this implies the following time constraint on individuals:

$$
\alpha_{t} s_{t} c_{t}+n_{t}+l_{t}=1
$$

Modeling the time cost of price search in this way has several advantages. First, the variety of goods increases with the size of the consumption bundle (Li 2013). It is more realistic to assume that one should devote a separate amount of time for each type of good to get lower quotes. For example, one should search among grocery stores to pay lower prices for groceries and among electronics stores to pay lower prices for computers. Second, if we were to assume that with search decision $s_{t}$ one could affect the entire consumption basket, the model would have unrealistic implications. For that case, as consumption increases price search will also increase. The reason is that with the same amount of price search individuals will lower the price of a larger consumption bundle. Hence, they will have more return from the search. To test the quantitative validity of the way that we model price search, we compare the relationship between prices paid and consumption implied in the model with the estimated empirical specifications. In particular, we find that the elasticity of price to consumption implied in our model is similar with the values reported in Aguiar and Hurst (2007).

\section{Quantitative Results}

As we showed in the theoretical section, the presence of price search can generate a difference between consumption and expenditure inequality profiles. Moreover, price search can also alter the asset accumulation of households, since it can serve as an insurance mechanism for adverse

\footnotetext{
${ }^{10}$ We specify the constant $\alpha$ as age-dependent to match the behavior of price paid over the life-cycle. With constant $\alpha$ the model generates an increasing profile of price paid over the life-cycle. In Section 4.3 we contrast the model with and without constant $\alpha$.
} 
shocks in addition to the standard insurance mechanisms like saving and labor supply. However, the presence of dynamic choices and uncertainty prevents us from deriving analytical results for the evolution of consumption, expenditure, and wealth inequality over the life-cycle. Thus, in this section, we quantitatively evaluate the significance of price search in an otherwise standard lifecycle model with incomplete markets and endogenous labor supply. We start with the calibration of the model.

\subsection{Calibration}

We calibrate the model in two stages. In the first stage, we directly use the values of several parameters that are well-established in the literature. This gives us an opportunity to understand the role of price search in the standard life-cycle models. The model period is set to one year, and each agent starts working at age 21 and retires at 65. Each agent starts his working life with an asset and income level drawn from a log-normal distribution with mean $\mu_{a / y}$ and variance $\sigma_{a / y}$. The values for these parameters are directly taken from Gourinchas and Parker (2003), who estimate $\mu_{a / y}$ as -2.79 and $\sigma_{a / y}$ to be 1.78 . We set $r=0.03$, which is roughly equal to the average return on risk-free investments in the US. The value of the relative risk-aversion parameter for consumption, $\sigma$, is set to a very standard value in the literature, $2 .^{11}$ The value of parameter $\gamma$, which pins down the intertemporal elasticity of substitution for leisure, is usually set greater than the value of $\sigma$ in the literature. Therefore, we set the value of $\gamma$ to 2.5. ${ }^{12}$ We borrow the parameters of the income process $-\beta_{0}, \beta_{1}, \beta_{2}, \rho, \sigma_{\varepsilon}^{2}$ and $\sigma_{v}^{2}$-from the literature. ${ }^{13}$

For the pension process, we follow the model of Guvenen (2007), which mimics the US Social Security system. After retirement, the pension of each agent is determined by the ratio of his wage in the last working period to the average wage in the last working period, $\frac{w_{T}}{\bar{w}}$. The pension function, $\Gamma\left(\frac{w_{T}}{\bar{w}}\right)$ is as follows:

$$
=\bar{w} \times \bar{n} \times \begin{cases}0.9 \frac{w_{T}}{\bar{w}}, & \text { if } \frac{w_{T}}{\bar{w}}<0.3 \\ 0.27+0.32\left(\frac{w_{T}}{\bar{w}}-0.3\right), & \text { if } 0.3<\frac{w_{T}}{\bar{w}}<2 \\ 0.81+0.15\left(\frac{w_{T}}{\bar{w}}-2\right), & \text { if } 2<\frac{w_{T}}{\bar{w}}<4.1 \\ 1.1 & \text { if } 4.1<\frac{w_{T}}{\bar{w}} .\end{cases}
$$

where $\bar{w}$ is the average wage paid in the economy and $\bar{n}$ the average number of hours worked.

Lastly, regarding the price function, we assume that price dispersion is normally distributed with mean $\mu_{p}=1$ and standard deviation $\sigma_{p}=0.27$, as documented in Kaplan and Menzio (2015).

\footnotetext{
${ }^{11}$ This number is very standard in both real business cycle literature and heterogeneous agents literature. An acceptable range for the value of $\sigma$ is usually from 1 to 10 .

${ }^{12}$ Storesletten et al. (2004), Chang and Kim (2007), and Kaplan (2012) use similar numbers.

${ }^{13}$ Among others, MaCurdy (1982), Storesletten et al. (2004), and Guvenen (2009) estimate values similar to those used in this paper.
} 
In the second stage, we estimate the remaining parameters to match chosen moments in the data. One specific assumption we make needs further discussion. We assume that the time cost of price search $(\alpha)$ changes deterministically over the working period. We make this assumption in order to better match the life-cycle evolution of prices paid that we observe in the data. This assumption can be rationalized due to several possible factors; specifically, experience, access to better technologies, or higher time endowment due to marriage. We should note that the model with constant time search cost produces almost identical results for the evolution of consumption and expenditure inequality. However, it also generates an increasing price paid over the lifecycle. ${ }^{14}$ We choose to match the life-cycle prices paid, in order to avoid any confusion that might result from unrealistic life-cycle price dynamics. To keep the number of parameters small, we assume that the time-search cost over the life-cycle follows a monotonically decreasing pattern, and summarize this function with only three parameters, which govern the curvature, level, and range of the function. More specifically, we impose the following functional form for time-search cost as a function of age:

$$
\begin{array}{cc}
\alpha_{t}=\underline{\alpha}+(\bar{\alpha}-\underline{\alpha})\left(\frac{T-t}{T-1}\right)^{\alpha_{p}} & \text { if } t \leq T \\
\alpha_{t}=\alpha_{T} & \text { if } t>T,
\end{array}
$$

where $\bar{\alpha}=\alpha+\epsilon_{\alpha}$ and $\underline{\alpha}=\alpha-\epsilon_{\alpha}$. This gives us three parameters, $\alpha, \alpha_{p}, \epsilon_{\alpha}$, to be estimated. In addition to these three parameters, we calibrate the discount factor, $\beta$, the relative weight of work disutility in the utility function, $\phi$, and the borrowing limit coefficient, $\underline{a}$. In total, we jointly estimate six parameters, $\beta, \phi, \underline{a}, \alpha, \alpha_{p}, \epsilon_{\alpha}$ to match the following moments: the wealth-to-income ratio (3.5) as documented in Heathcote et al. (2010), mean hours worked (0.35), the fraction of borrowers (0.17) as estimated from the Survey of Consumer Finance, the average price paid (1.0) as normalization, and the life-cycle profile of average prices paid, as documented in Aguiar and Hurst (2007) and Kaplan and Menzio (2015).

\subsection{Results}

Table 2 presents the model-generated moments against their data counterparts. As expected, the model matches all the targeted moments quite well. Further, Figure 1(b) shows the life-cycle profile of average prices paid by households generated in the model. The pattern is consistent with the estimates of Aguiar and Hurst (2007) and Kaplan and Menzio (2015). Figure 1(a) plots the implied relation between price search and price paid that is implied by the model. Given that price dispersion is distributed normally, this relation is quite close to the functional form assumed in Aguiar and Hurst (2007) and in our theoretical section. ${ }^{15}$

\footnotetext{
${ }^{14}$ See Section 4.3 for details.

${ }^{15}$ If we run the regression $\log (p)=\theta_{0}+\theta_{1} \log (s)+\epsilon$, we get $\theta_{1}=-0.216$ and $R^{2}$ as 0.998 . This estimate of $\theta_{1}$ is in the range of the estimates reported in Aguiar and Hurst (2007).
} 


\section{Table 1: Benchmark Model Parameters}

\begin{tabular}{cll}
\hline \hline Parameter & Explanation & Value \\
\hline \hline & Externally Set & 0.03 \\
$\sigma$ & Risk-free interest rate (U.S. data) & 2 \\
$\gamma$ & Intertemporal elasticity of substitution for consumption (various sources) & 2.5 \\
$\rho_{2}$ & Intertemporal elasticity of substitution for leisure (various sources) & 0.96 \\
$\sigma_{\varepsilon}^{2}$ & Persistence of earning shocks (various sources) & 0.062 \\
$\sigma_{v}^{2}$ & Variance of transitory earning shocks (various sources) & 0.015 \\
$\mu_{a / y}$ & Variance of persistent earning shocks (various sources) & -2.79 \\
$\sigma_{a / y}$ & Mean of initial asset/income dist (Gourinchas and Parker 2003) & 1.78 \\
$\beta_{0}$ & Variance of initial asset/income dist (Gourinchas and Parker 2003) & 0.4 \\
$\beta_{1}$ & Constant of the wage process & 0.032 \\
$\beta_{2}$ & Return to experience & -0.00035 \\
$\mu_{p}$ & Return to experience-squared & 1 \\
$\sigma_{p}$ & Mean of price dispersion & 0.27 \\
\hline \hline & Std of price dispersion & 0.952 \\
\hline$\beta$ & Internally Calibrated & 15.8 \\
$\phi$ & Discount factor & 0.426 \\
$a$ & Weight of disutility of work in utility & 0.11 \\
$\alpha$ & Borrowing limit & 2.69 \\
$\alpha_{p}$ & Time search cost parameter & 0.43 \\
$\epsilon_{\alpha}$ & Time search cost parameter & \\
\hline \hline
\end{tabular}

Notes: See text for definitions and sources of parameter values.

Table 2: Benchmark Model-Moments

\begin{tabular}{lll} 
Moment & Data & Model \\
\hline \hline Wealth-income ratio & 3.5 & 3.5 \\
Mean hours worked & 0.35 & 0.35 \\
Fraction of borrowers & 0.17 & 0.17 \\
Average price paid & 1.0 & 1.0 \\
\hline \hline
\end{tabular}

Notes: See text for definitions and sources of data moments. 


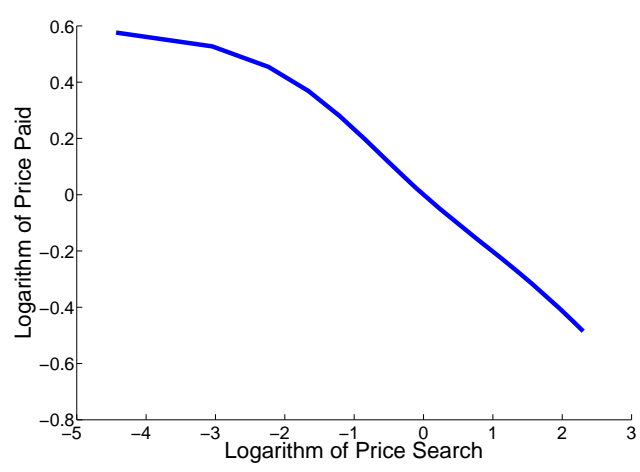

(a) Price Function

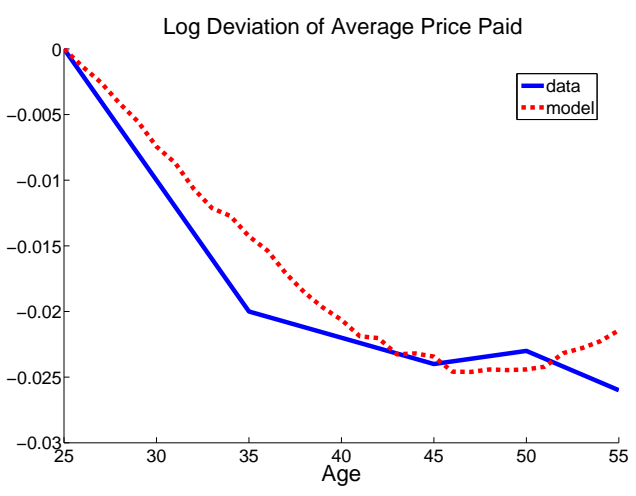

(b) Life-Cycle Prices

Figure 1: Average Price Paid - Model vs Data: The source is A.C. Nielsen Homescan data set of Aguiar and Hurst (2007). The figure on the left panel plots the life-cycle profile of average prices paid over the life-cycle both in the model and the data. It shows the deviation of prices paid from age 0 , which corresponds to age 25 in the data. The figure on the right panel plots the log of price paid as a function of log of price search.

Figure 2(b) compares the model with data in terms of average prices paid by income quintiles. In the model, the average price paid in the highest earning quintile is 0.22 log points higher than that of the lowest earning quintile. The corresponding number is 0.20 log points in the data. ${ }^{16}$

Figure 2(a) shows the life-cycle profile of average hours worked, in both the model and the data. Although the model does not target the life-cycle profile of hours worked, it matches the pattern in the data apart from the time prior to retirement. In the data, the number of hours worked decreases substantially before retirement. While the model generates a decreasing pattern of hours worked, it does not generate the size of the decline right before retirement. Factors like early retirement, the added-worker effect, and age-dependent unemployment shocks can help to reconcile the model with the data. The model analyzed by Kaplan (2012) aims to match life-cycle labor supply dynamics. He argues that involuntary unemployment and non-separability in the disutility of the extensive and intensive margins of hours worked are necessary to match the lifecycle labor supply behavior. We find the model's current match of the data to be sufficient and thus do not pursue further to improve. ${ }^{17}$

Given the success of the model in matching certain important features of the data, we next present the statistics of interest for this paper. We start with the determinants of price search decision. Section 2 predicts that in our model, price search should be negatively correlated with wage, and non-monotone in wealth. More specifically, when labor supply is positive, which happens when wealth is not very high, price search depends only on wage and is independent of

\footnotetext{
${ }^{16}$ We borrowed the data set (A.C. Nielsen Homescan data) of Aguiar and Hurst (2007) for this analysis.

${ }^{17}$ However, we do a robustness analysis (not reported in the paper) in which we exogenously match the life cycle labor supply data. In this case, the gap between expenditure and consumption inequalities increases.
} 


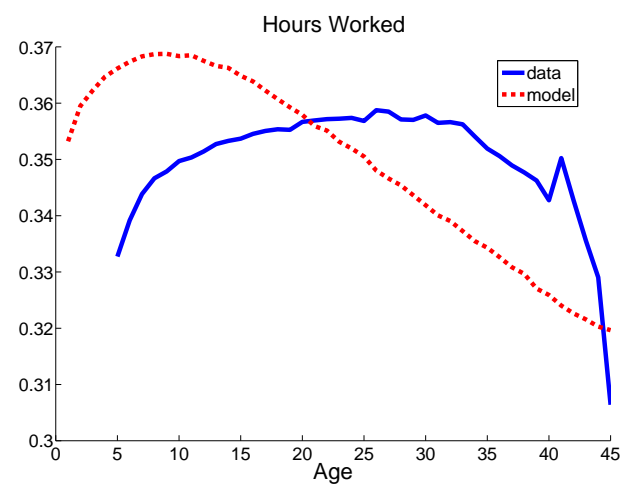

(a) Mean Hours Worked

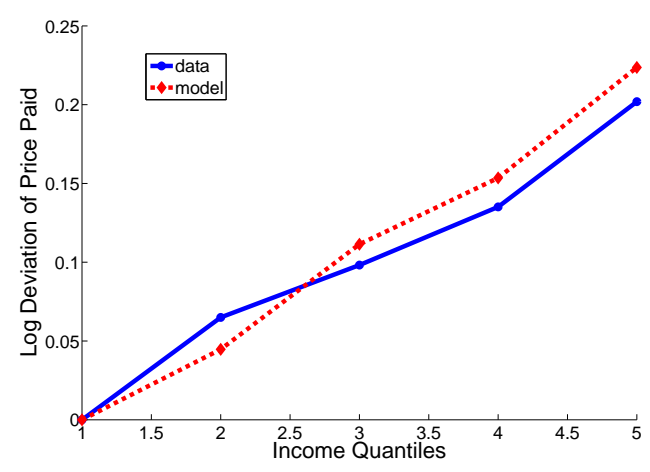

(b) Income

Figure 2: Model vs Data: The figure on the left panel plots the life-cycle profile of average hours worked in the model and the data. The figure on the right panel plots the average price paid for different income quintiles in the model versus the data. Empirical relationship between the level of earnings and prices is calculated using the A.C. Nielsen Homescan data set of Aguiar and Hurst (2007). The sample is divided into quintiles in terms of labor income levels. We calculate the mean log price for each good and income group across shopping trips. We then average over goods by weighting with the number of shopping trips. In the data, we divided the sample into quintiles in terms of labor income, calculate average price paid by each quintile, and then draw the log deviations from the 1st quintile. The model counterpart is derived by imposing similar sample restrictions as in the data. Specifically, we report the price/income data for the age group 25-75 with income higher than $25 \%$ and lower than $200 \%$ of the median income.

wealth. However, when labor supply becomes zero, which happens when wealth is sufficiently large, price search becomes negatively correlated with wealth.

Figures 3(a) and 3(b) confirm these results. Figure 3(a) shows that, consistent with the predictions of Lemma 1, as wealth increases price search initially stays constant. However, after a sufficiently large wealth has been achieved (the critical level of debt depends on wage), it starts to decrease, as predicted by Lemma 2. The turning point coincides with the wealth level when labor supply becomes zero. The same figure also shows the effect of the wage on price search. ${ }^{18} \mathrm{~A}$ higher wage implies higher labor supply and lower price search, as stated in Lemma 1. Another important observation is that as wealth increases price search for different income groups converges to a low level. Thus, the role of wealth becomes the dominant determinant of price search as individuals become wealthier.

Figure 3(b) also shows that, not surprisingly, as a household ages, price search increases. This is due to the combination of two effects. On the one hand, as wage rate and wealth increase, on average, with age, price search decreases. On the other hand, more directly, the cost of price search increases as a household ages (we calibrated the cost parameter to match the life-cycle dynamics of prices). So, this effect mechanically decreases price search over the life-cycle.

\footnotetext{
${ }^{18}$ Wages correspond to different levels of persistent shock. The plot with transitory shocks generates the same qualitative results.
} 


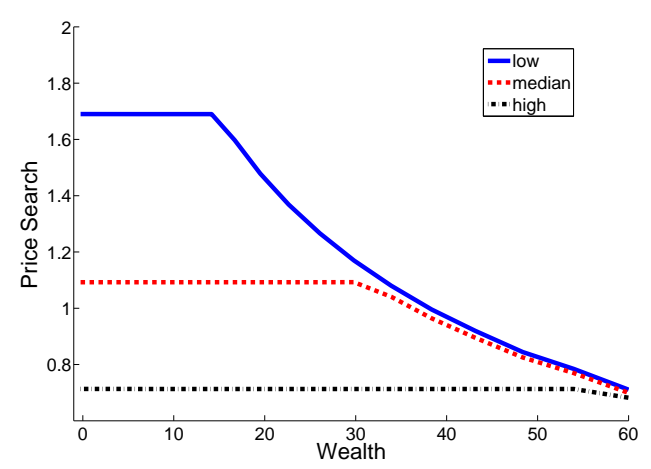

(a) Wealth and Wage

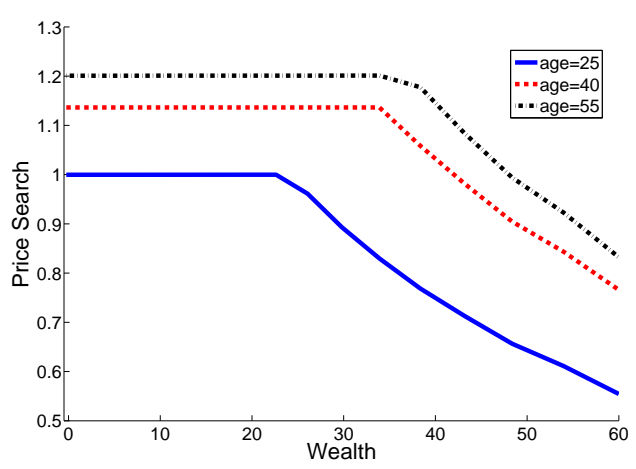

(b) Wealth and Age

Figure 3: Determinants of Price Search: The figure shows model generated price search decision as a function of wealth, wage and age. The price search decisions are shown for a household at the age 40 with median level of both persistent and transitory shocks.

\subsubsection{Age-Inequality Profiles of Consumption and Expenditure}

Given the determinants of price search, we now analyze the quantitative effects of price search on expenditure and consumption inequality. We measure inequality by the variance of the log of the variables.

In earlier studies, in general, consumption was assumed to be equal to expenditure, which implied exactly equal age-inequality profiles for consumption and expenditure. In this paper, as our key contribution, we differentiate consumption from expenditure by introducing price search into the model. Our model predicts a substantially lower consumption inequality than expenditure inequality throughout the life cycle. Moreover, the difference between consumption inequality and expenditure inequality increases over the life cycle. As Figure 4(a) shows the cross-sectional variance of log expenditure increases by more than $33 \log$ points over the life cycle, while the variance of $\log$ consumption increases by about $21 \log$ points. This is almost a 40 percent reduction in the increase in inequality over the life-cycle.

In order to understand the gap between consumption and the expenditure inequalities throughout the life cycle, we decompose the expenditure inequality as follows:

$$
\operatorname{var}(\log e)=\operatorname{var}(\log c)+\operatorname{var}(\log p)+2 \operatorname{cov}(\log c, \log p)
$$

We calculate each component of $\operatorname{var}(\log e)$ from the model-generated data. As can be seen from Figure $4(\mathrm{~b})$, around $63 \%$ of the increase is due to the increase in the variance of log consumption, around $34 \%$ is due to the increase in the covariance between consumption and price, and the remaining $3 \%$ to the increase in the variance of prices paid. 


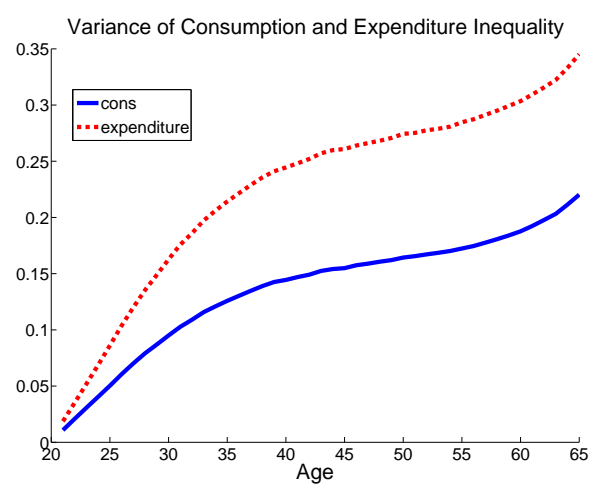

(a) Expenditure vs Consumption Inequality

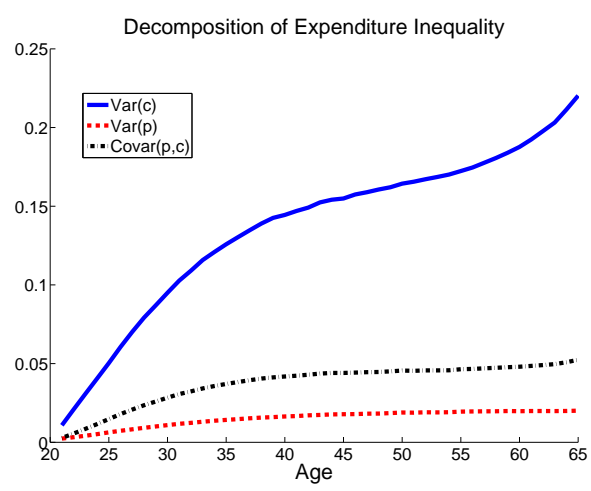

(b) Decomposition of Expenditure Inequality

Figure 4: Expenditure and Consumption Inequality: The figure on the left plots the life-cycle profile of consumption and expenditure inequality measured by the variance of $\log$ of the variables. The figure on the right decomposes the expenditure inequality into its components: variance of consumption, variance of prices and covariance between consumption and prices.

One of the main reasons for this result is that price search and consumption over the lifecycle are negatively correlated. We can see this by analyzing the covariance between search and consumption. Figure 5(a) plots the life-cycle profile of the covariance between consumption and price search. As expected, it is negative. Moreover, it becomes more negative as the household ages. This is because average wealth and wealth inequality increase with age. One implication of this is that the number of people who decrease their search as their wealth increases is larger for older people (see Figure 3(b)). As wealth and consumption are highly correlated this gives our result.

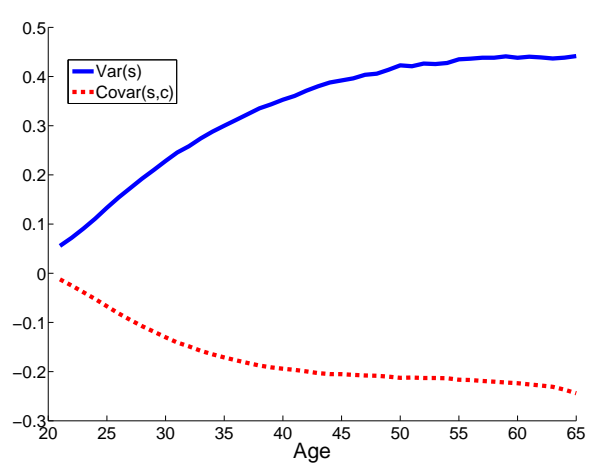

(a) Price Search and Consumption Inequality

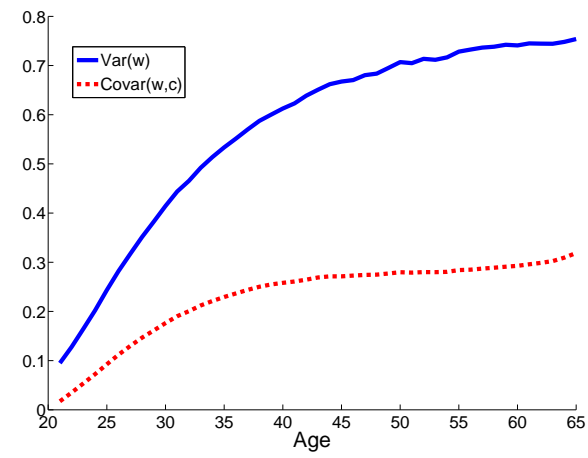

(b) Wage and Consumption Inequality

Figure 5: Decomposition of Expenditure Inequality: The figure on the left plots the life-cycle profile of the variance of log price search and covariance of log of price search and log of consumption. The figure on the right plots the life-cycle profile of the variance of $\log$ of wage and covariance of $\log$ of wage and $\log$ of consumption.

Lastly, as in Lemma 4, variance of log expenditure can be decomposed into variance of log 
consumption, variance of log wages, and covariance of log wages and log consumption: Figure 5(b) shows the evolution of wage inequality and the covariance of wages and consumption over the life-cycle. As the data indicate, wage inequality substantially increases over the life-cycle. However, the covariance of wages and consumption is also positive and increases significantly over the life-cycle. Our results reveal that, in particular, the covariance of consumption and wages has a very significant effect on the gap between consumption and expenditure inequality. ${ }^{19}$

\subsubsection{Measuring the Partial Insurance Role of Price Search}

In this section, we compute the amount of partial insurance gained through price search. In order to quantify the partial insurance role of price search, we resolve the model without price search. To separate out the effect of price search, we recalibrate the discount factor, $\beta$, the borrowing limit, $\bar{a}$, and the disutility of work, $\phi$, to match the same statistics for wealth-income ratio, mean hours worked, and the fraction of households with debt. This calibration results in $\beta=0.95, \phi=51.4$, and $\underline{a}=0.43$, generating a wealth-income ratio of 3.5 , mean hours worked as $35 \%$, and the fraction of borrowers as $17 \%$.

Following Blundell et al. (2008) and Kaplan and Violante (2010), we calculate the insurance coefficients as follows:

$$
\phi^{\epsilon}=1-\frac{\operatorname{cov}\left(\Delta c_{i t}, \epsilon_{i t}\right)}{\operatorname{var}\left(\epsilon_{i t}\right)}
$$

where the insurance coefficient of shock $\epsilon$ is denoted by $\phi^{\epsilon}$. In the complete markets framework, $\phi^{\epsilon}=1$ due to the fact that idiosyncratic shocks do not affect consumption, that is $\operatorname{cov}\left(\Delta c_{i t}, \epsilon_{i t}\right)=0$. In an autarky environment, consumption is in a one-to-one mapping relation to idiosyncratic shocks, and thus $\phi^{\epsilon}=0$. Under incomplete markets, one would expect the insurance coefficients to be between 0 and 1 .

Using US micro-level consumption data, Blundell et al. (2008) estimate the insurance coefficients as 0.36 and 0.95 for permanent and transitory shocks, respectively. ${ }^{20}$ Kaplan and Violante (2010) generate similar coefficients in a simulated economy using a life cycle model with incomplete asset markets, inelastic labor supply, and idiosyncratic income shocks where agents face natural borrowing limits.

Using equation (12), we compute the insurance coefficients for the entire population in our benchmark economy. As shown in Table 3, in the case of no price search, the computed insurance

\footnotetext{
${ }^{19}$ Given the benchmark value of price elasticity of search, and the model-generated changes in the variance of wages and covariance between wages and consumption, we can conclude that $75 \%$ of the gap between expenditure and consumption inequality is due to the increase in the covariance of consumption and wages, while the rest is due to increase in the variance of wages.

${ }^{20}$ They use the Panel Study of Income Dynamics (PSID) and Consumer Expenditure Survey (CEX) data. See Blundell et al. (2008) for details.
} 
coefficients are 0.61 (persistent shock) and 0.91 (transitory shock) for both consumption and expenditure. ${ }^{21}$ With price search, the corresponding insurance coefficient for consumption increases to 0.72 for the persistent shock and 0.99 for the transitory shock. ${ }^{22}$ The corresponding coefficients for expenditure are 0.56 and 0.83 , respectively. In the model with price search, the consumption insurance coefficients of persistent and transitory shocks are improved by $0.11(18 \%)$ and 0.08 (9\%), respectively. These results show that price search plays a significant role in insuring the individuals against adverse income shocks. Moreover, a model without price search undermines the actual degree of consumption insurance individuals are able to do.

Table 3: Insurance Coefficients

\begin{tabular}{|c|c|c|c|c|}
\hline \multirow[b]{3}{*}{ Transitory } & \multicolumn{2}{|c|}{$\mathrm{w} /$ Price Search } & \multicolumn{2}{|c|}{ w/out Price Search } \\
\hline & Expenditure & Consumption & Expenditure & Consumption \\
\hline & .83 & .99 & .91 & .91 \\
\hline Persistent & .56 & .72 & .61 & .61 \\
\hline
\end{tabular}

Notes: The insurance coefficients are calculated using equation (12). The coefficients are calculated for the entire population. See text for details.

\subsection{Robustness Analysis}

In this section, we provide several robustness analysis with respect to some important parameters of the model, specifically with respect to the parameters of price and utility functions. In each of these counterfactuals, we recalibrate the discount factor $(\beta)$, the disutility of labor $(\phi)$, the borrowing limit constant $(\underline{a})$, and parameters related to the time cost of price search $\left(\alpha, \alpha_{p}, \epsilon_{\alpha}\right)$ to match the wealth-income ratio, mean hours worked, fraction of borrowers, mean price paid and life-cycle profile of prices paid.

Risk Aversion: In the models with incomplete markets, risk aversion is an important parameter that determines the desire for consumption smoothing. It is well-known within these models that as risk aversion increases consumption inequality decreases. This fact is also confirmed by Figure 6(a) in our model. However, the same fact also decreases the expenditure inequality as is confirmed in Figure 6(b). So, it is not clear what happens to the difference between expenditure and consumption inequality. However, equation (9) shows that an increase in risk aversion only affects the difference between expenditure and consumption inequality through its effect on the variance of consumption and the covariance of consumption and wages. We know that higher risk

\footnotetext{
${ }^{21}$ Note that consumption in this case is equal to expenditure by definition.

${ }^{22}$ Using natural borrowing limits, Kaplan and Violante (2010) compute insurance coefficients for consumption in the range of $0.30-0.52$ (depending on the persistence of the shocks) for persistent shocks and 0.92-0.93 for transitory shocks.
} 
aversion, which implies a higher desire for consumption smoothing, decreases both the variance of consumption and the covariance of consumption and wages, as is also shown in Figure 7(b). Thus, the difference between expenditure and consumption inequality decreases as risk aversion increases, which is also confirmed in Figure 7(a). However, the difference is still large, which suggests that the role of price search remains quantitatively important across different risk aversion parameters.

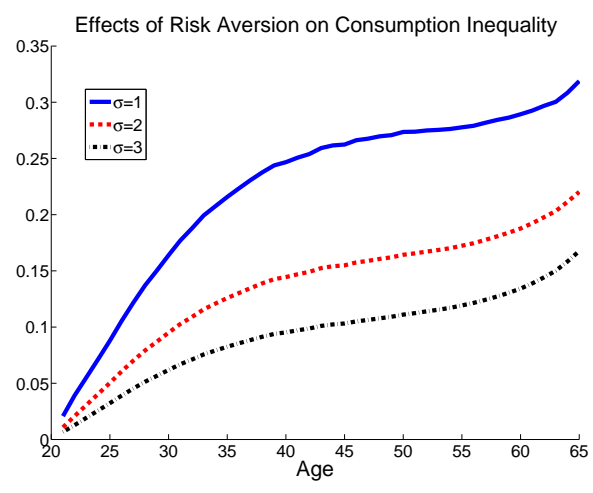

(a) Consumption

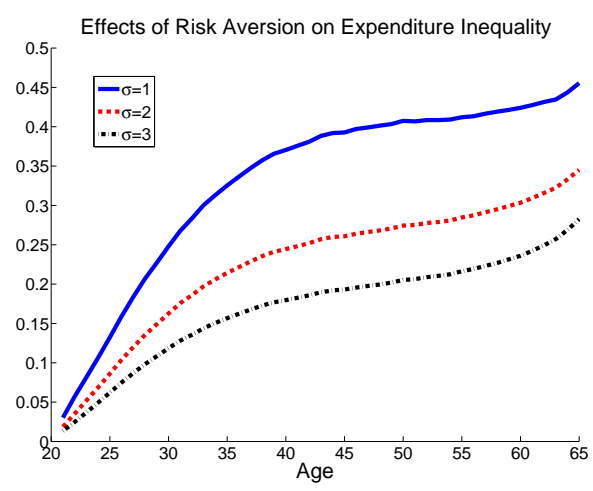

(b) Expenditure

Figure 6: The Effects of Risk Aversion: The figure shows the effects of risk aversion on the variance of log expenditure (right panel) and variance of log consumption (left panel).

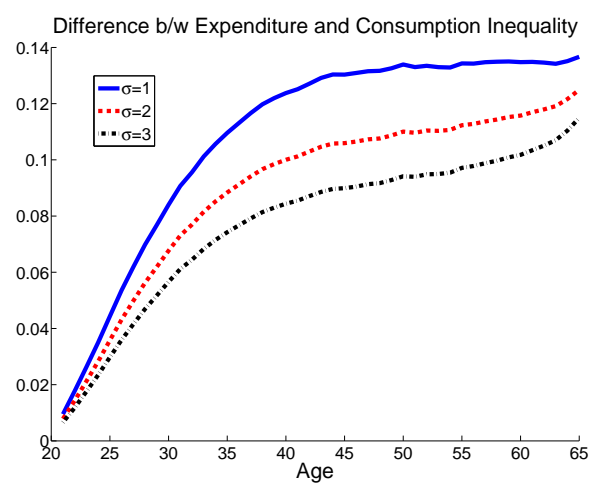

(a) Difference

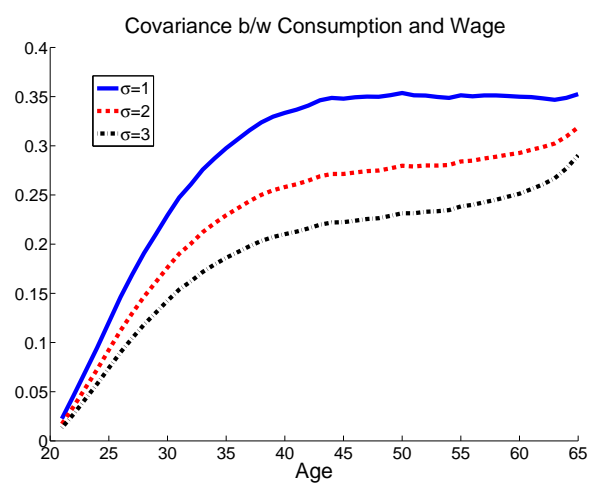

(b) $\operatorname{Covar}(\log c, \log w)$

Figure 7: The Effects of Risk Aversion: These figures show the effects of risk aversion on the difference between variance of log expenditure and variance of log consumption (left panel), and on the covariance between $\log$ consumption and log wages (right panel).

Frisch Elasticity: Frisch elasticity is an important parameter in our model. It affects the insurance role of labor supply so as to avoid the fluctuations in consumption generated by exogenous and stochastic movements in wages. In our model, Frisch elasticity is equal to $\frac{1}{\gamma}$. As Frisch elasticity increases, labor supply becomes more elastic, and labor supply can play a more significant role in insuring against wage fluctuations. Therefore, higher Frisch elasticity should imply lower con- 
sumption and expenditure inequalities. This is confirmed by Figures 8(a) and 8(b) in our model. As these figures show, a decrease in $\gamma$, which translates into a higher Frisch elasticity, decreases both expenditure and consumption inequality. Although the net effect on the difference between expenditure and consumption inequality appears ambiguous, equation (9) shows that this difference depends on the variance of consumption and the covariance of consumption and wages. A decrease in $\gamma$ decreases both of these terms, as is also shown in Figures 8(a) and 9(b). Thus, we expect the difference between expenditure and consumption inequality to decrease as $\gamma$ decreases, which is confirmed by Figure 9(a). While qualitatively the results are as expected, quantitative effects of Frisch elasticity on the key findings are limited. Therefore, it is reasonable to conclude that our findings are robust to changes in the value of Frisch elasticity parameter.

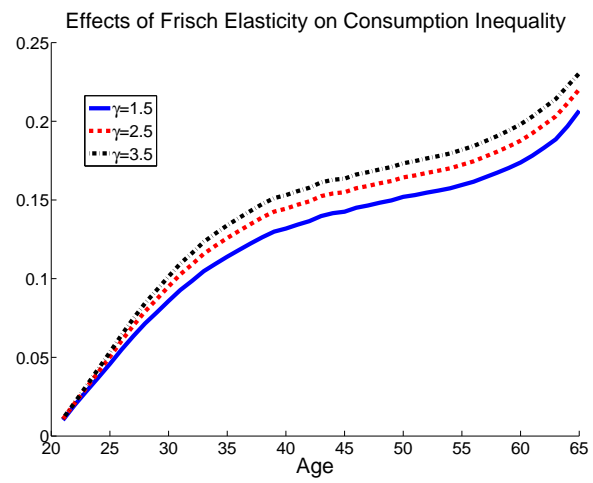

(a) Consumption

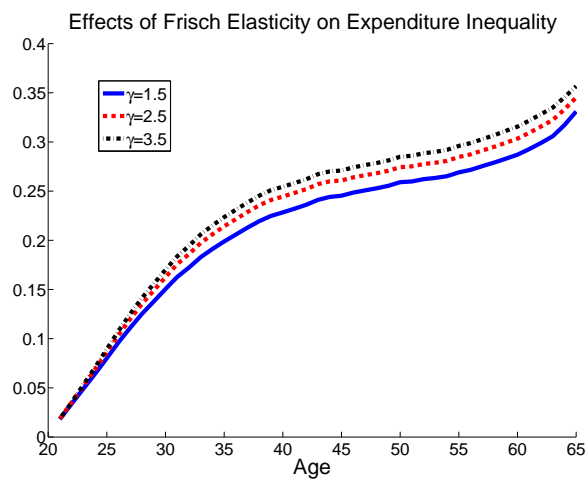

(b) Expenditure

Figure 8: The Effects of Frisch Elasticity: These figures shows the effects of Frisch Elasticity on the variance of log expenditure (right panel) and variance of log consumption (left panel).

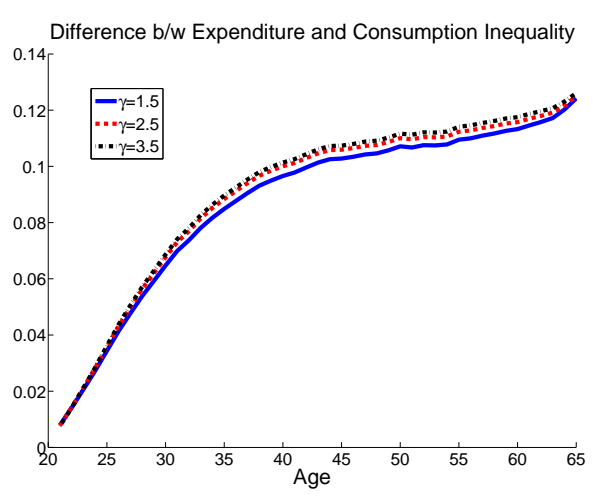

(a) Difference

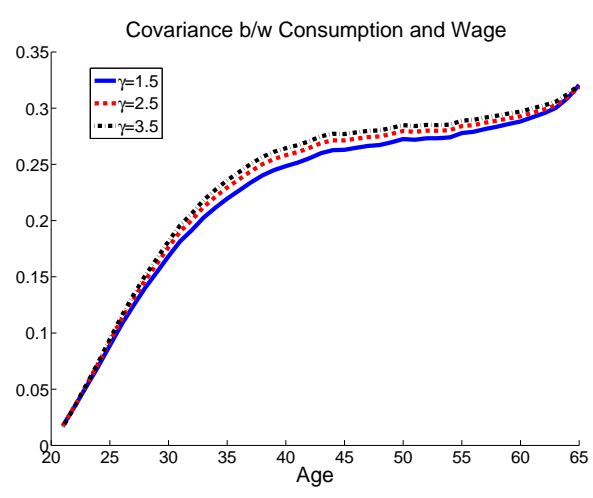

(b) $\operatorname{Covar}(\log c, \log w)$

Figure 9: The Effects of Frisch Elasticity: These figures shows the effects of Frisch Elasticity on the difference between variance of log expenditure and variance of log consumption (left panel), and on the covariance between log consumption and log wages (right panel). 
Price Dispersion If there were no price dispersion in the model, there would be no returns to price search. Therefore, no one would search for prices and everyone would pay the same price. In that case, consumption and expenditure would be equal to each other. This reasoning implies that price dispersion is crucially important in the model. For the quantitative exercise we calibrate the price dispersion from data (Kaplan and Menzio (2015)). However, we find it informative to perform a robustness analysis to have a better understanding of quantitative importance. The analysis provides additional insight regarding how expenditure and consumption inequality can evolve for different goods if they have a different price dispersion.

The results show quantitatively strong effects of price dispersion. As is expected, Figure 10 (a) shows that consumption inequality decreases with price search. However, as shown in Figure 10(b), the relationship between expenditure inequality and price search appears to be nonmonotonic. Lower consumption inequality due to higher price dispersion pushes expenditure inequality down. On the other hand, a higher variance of price paid increases expenditure inequality. The most significant effect of price dispersion is on the difference between expenditure and consumption inequalities, as can be seen in Figure 11(a). The difference increases to $20 \log$ points when dispersion is 0.5 , and decreases to around $4 \log$ points when dispersion is 0.1 . These findings indicate that the difference that we have found between overall consumption and expenditure inequalities can be very different across different sectors.

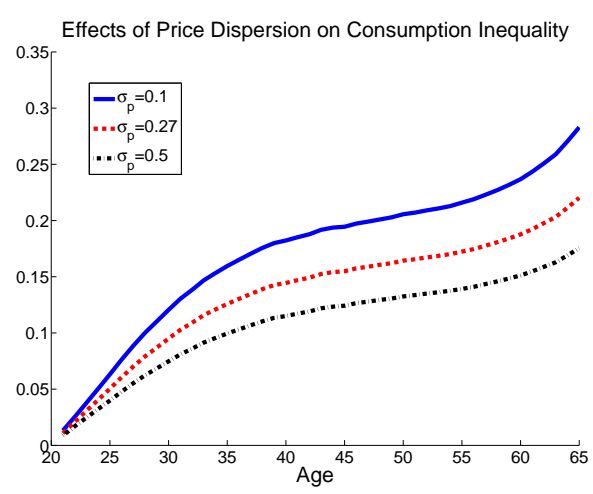

(a) Consumption

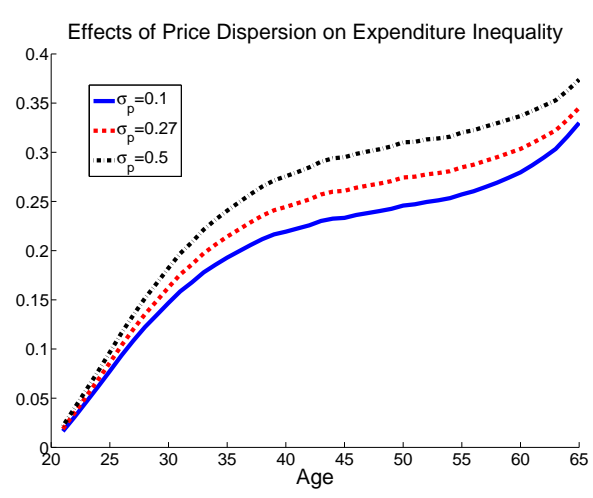

(b) Expenditure

Figure 10: The Effects of Price Dispersion: These figures show the effects of price dispersion on the variance of log expenditure (right panel) and variance of log consumption (left panel).

Time Cost of Price Search: Time cost of receiving $s$ draws equals $\alpha_{t} s c^{\psi}$. There are two important parameters of this search technology. The first is the time cost of price search, $\alpha_{t}$, which is assumed to be age dependent in the benchmark model to match the average price profile over the life-cycle. The second parameter for the search technology, $\psi$, relates to how time cost of search increases with consumption. Up to this point we assumed that it is linear, $\psi=1$. As a robustness exercise, 


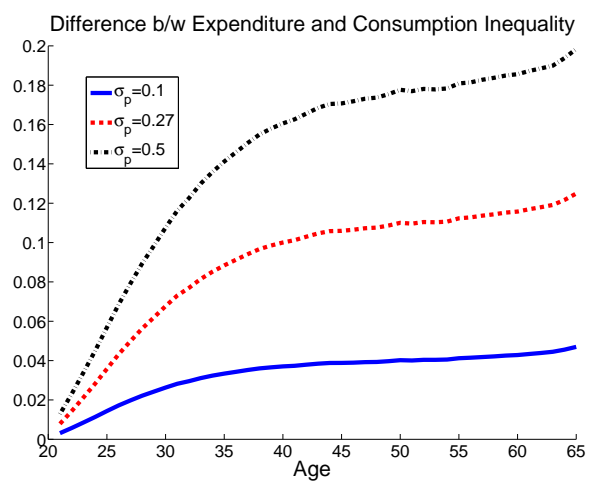

(a) Difference

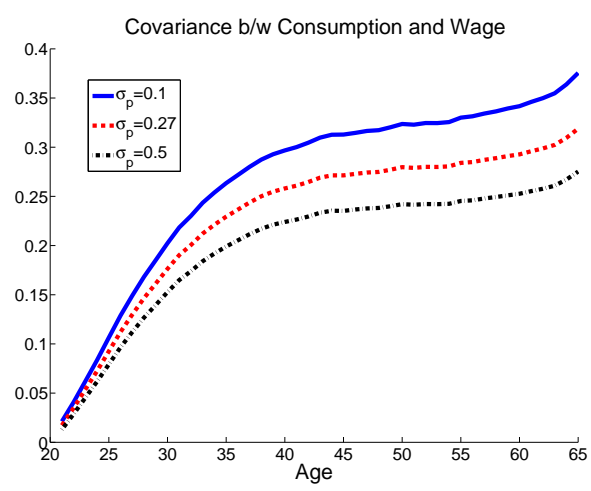

(b) $\operatorname{Covar}(\log c, \log w)$

Figure 11: The Effects of Price Dispersion: These figures show the effects of price dispersion on the difference between variance of log expenditure and variance of log consumption (left panel), and on the covariance between log consumption and log wages (right panel).

in this section, we analyze the cases in which it is concave, $\psi<1$, or convex, $\psi>1$. We explore the effects of these two parameters on the evolution of consumption and expenditure inequalities.

$\alpha_{t}$ : We start with the role of $\alpha$. More specifically, we vary the constant $\alpha$ in the functional form for the time cost of price search $\left(\alpha_{t}\right)$ and kept $\alpha_{p}, \epsilon_{\alpha}$ constant in the estimation. For each values of $\alpha$ we re-calibrate $\beta, \phi$, $\underline{a}$ to match the wealth-income ratio, the mean hours worked, and the fraction of borrowers in the data.

In the theoretical section we showed that when labor supply is exogenous and/or zero $\alpha$ determines the elasticity of price search to wealth. In that case it may have large implications for inequality. When labor supply is endogenous, however, $\alpha$ appears only in the constant term. Therefore, in that case $\alpha$ affects only the level of average price search. Hence, we do not expect large effects when labor supply is endogenous. Figures 12(a)-13(b) show our results. It is clear that $\alpha$ has almost negligible effects on the dynamics of inequality. However, it has significant effects on the evolution of prices paid over the life-cycle.

We also check for the effects of keeping $\alpha_{t}$ constant over the life-cycle, i.e. $\alpha_{t}=\alpha$. For this case, we re-calibrate $\beta, \phi, \underline{a}, \alpha$ to match wealth-income ratio, mean hours worked, fraction of borrowers, and average price paid in the data. As shown in Figure 14(a), keeping $\alpha_{t}$ constant has almost negligible effects on the difference between expenditure and consumption inequality. ${ }^{23}$ However, as shown in Figure 14(b), constant $\alpha$ generates an increasing profile of average prices paid over the life-cycle, which is counterfactual. Although, in the model, we do not provide a micro-foundation for the age-dependent time cost of price search, our main point in the paper, which concerns the

\footnotetext{
${ }^{23}$ In order to save space, we do not provide the graphs for the evolution of expenditure and consumption inequalities here. However, for both expenditure and consumption inequalities, the effects are negligible.
} 


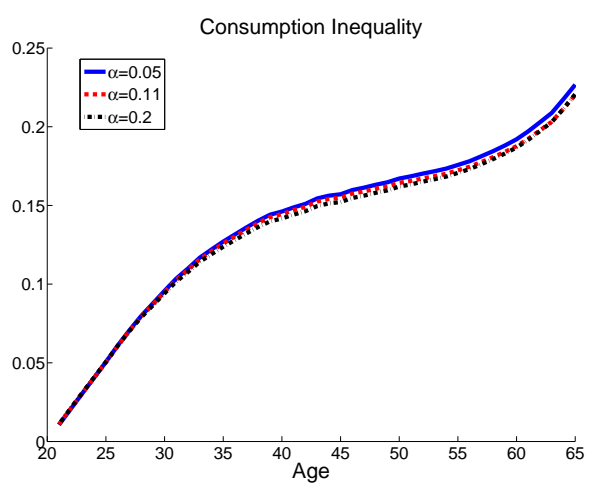

(a) Consumption

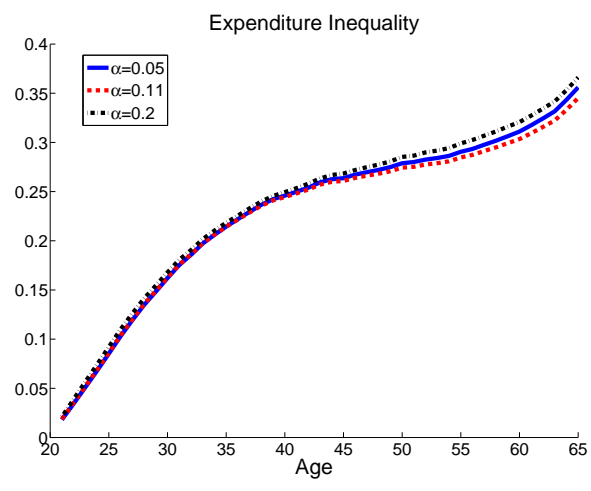

(b) Expenditure

Figure 12: The Effects of Time Cost of Search $(\alpha)$ : These figures show the effects of $\alpha$, a parameter governing time cost of search on the variance of log expenditure and variance (left panel) of log consumption (right panel).

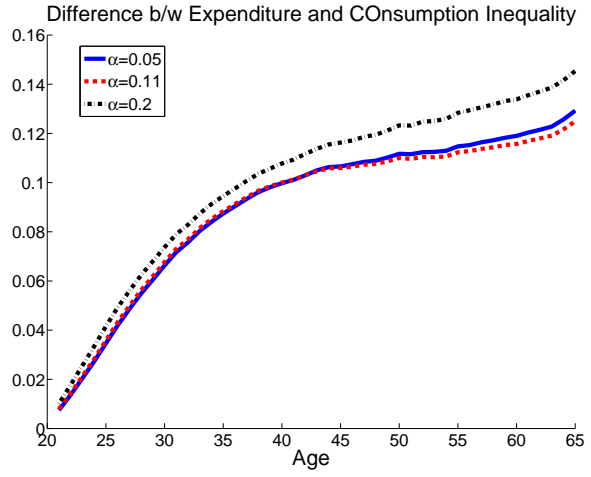

(a) Difference

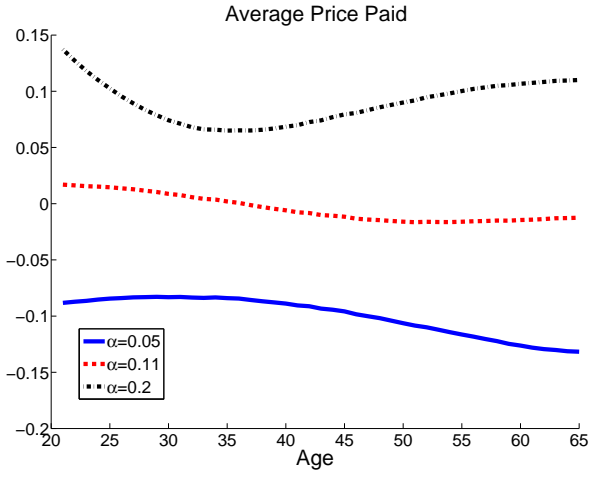

(b) Price Paid

Figure 13: The Effects of Time Cost of Search $(\alpha)$ : The figure on the left shows the effect of time cost of search on the difference between variance of log expenditure and variance of log consumption. The figure on the right plots the average price paid over the life-cycle for different parameters of time cost of price search, $\alpha$. 
difference between expenditure and consumption inequality, is not affected by this assumption.

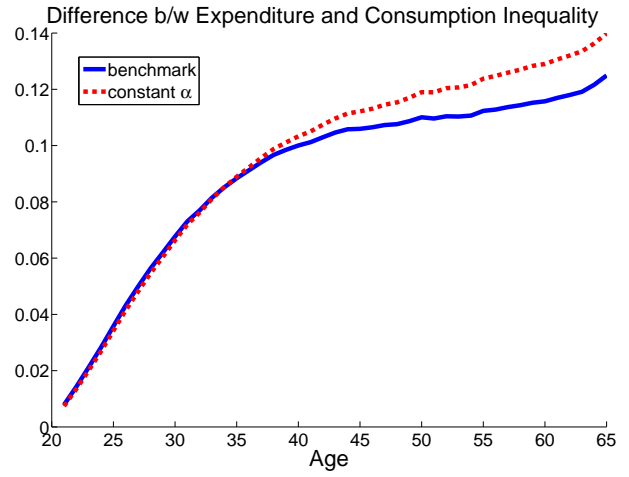

(a) Difference

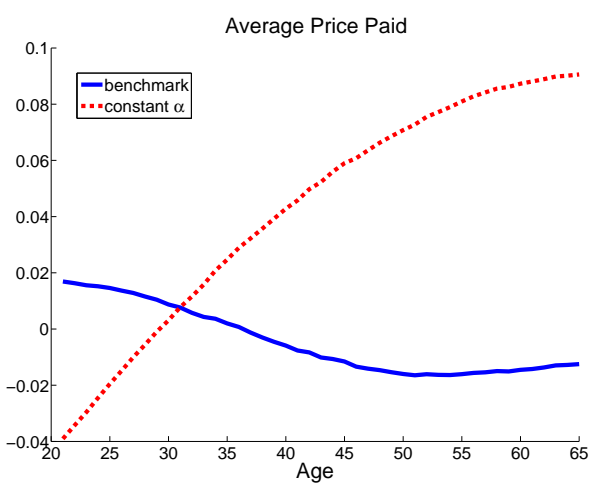

(b) Price Paid

Figure 14: The Effects of Time Cost of Search $(\alpha)$ : The figure on the left shows the effect of $\alpha$, a parameter governing time cost of search on the difference between variance of log expenditure and variance of log consumption. The figure on the right plots the average price paid over the life-cycle for different parameters of time cost of price search, $\alpha$.

$\psi$ : We find large effects of $\psi$ on consumption and expenditure inequalities. $\psi$ measures how the time cost of search increases with consumption. Unfortunately, there is no prior study that we can rely on to pin down this parameter. In the benchmark model we assumed that $\psi$ is 1 . Our intuition was that as consumption increases the variety of goods consumed also increases. From Li (2013) we know that it is almost linear for food consumption. If consumers dedicate separate times to different goods then we can expect that $\psi$ will be close to 1 . However, one can come up with other scenarios where $\psi$ is smaller or greater than 1 . For example, if the variety of goods consumed increases it may be difficult to search for each variety separately if there are fixed costs. In that case a value of $\psi>1$ will represent the behavior more accurately. It is also possible to have $\psi<1$ if variety increases nonlinearly with consumption of, for example, non-food consumption goods.

Having these concerns in mind we find it useful to do a robustness analysis for three different values of $\psi: 0,1$ (our baseline parameter) and 2. Our results shows that $\psi$ has large effects. Expenditure inequality (Figure 15(b)) increases more and consumption inequality (Figure 15(a)) increases less (around 5 log points each) for higher $\psi$. Combining these two effects results in an even larger role of $\psi$ on the difference between consumption and expenditure inequality (Figure 16(a)). Compared to our benchmark, when $\psi$ is zero the difference between expenditure and consumption inequality is about $4 \log$ points lower. The difference becomes around 4 log points larger when we set $\psi$ to 2 .

The intuition is as follows. As $\psi$ gets larger it becomes more costly for wealthier and higher 
income groups to search for lower prices as they can consume more. Therefore, individuals with more wealth and higher income will spend less time on price search and will consume less compared to lower $\psi$ levels. As a result, the level of consumption of the upper part of the consumption distribution shifts downward making the consumption inequality smaller. The same reasoning also implies a larger expenditure inequality as prices paid by higher wealth and income groups will increase with $\psi$.

Our analysis of $\psi$ reveal that to precisely quantify the role of price search on expenditure and consumption inequality the value of $\psi$ is crucial. On the other hand, even when $\psi=0$ the gap between expenditure and consumption inequality is larger than $6 \log$ points. While it is around $5 \mathrm{log}$ points lower than our baseline results, it still corresponds to about $20 \%$ of expenditure inequality.

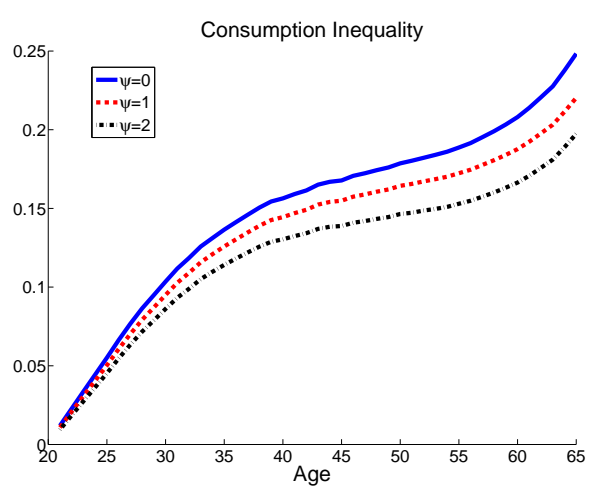

(a) Consumption

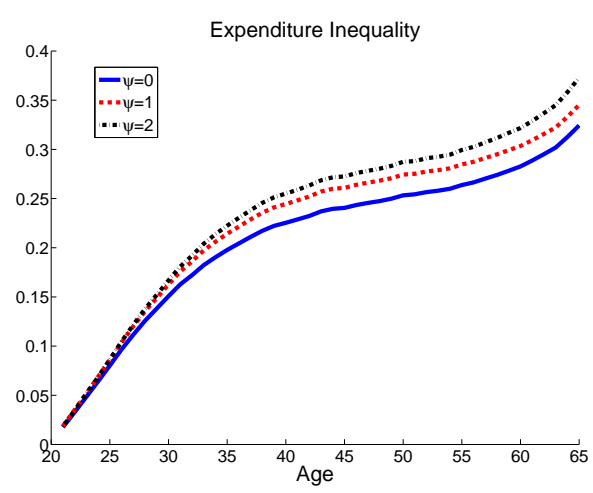

(b) Expenditure

Figure 15: The Effects of Time Cost of Search $(\psi)$ : These figures show the effects of $\psi$, a parameter governing time cost of price search, on the variance of log expenditure (left panel) and variance of log consumption (right panel).

\section{Discussion and Conclusion}

In this paper, we studied the role of price search on the age-inequality profiles of consumption and expenditure. Particularly, we introduced price search decision into a life-cycle model, differentiated consumption from expenditure, and studied the joint behavior of price search, labor supply, and consumption/saving decisions. The model predicts an increasing age-inequality profile for consumption and expenditure. Our quantitative exercise, using an estimated income process and price search functions from the literature, predicts that consumption inequality is significantly lower than expenditure inequality when agents are allowed to search for prices. A plausibly calibrated version of our model predicts that the cross-sectional variance of log consumption is about 40 percent smaller than that of the log expenditure throughout the life cycle. However, in the 


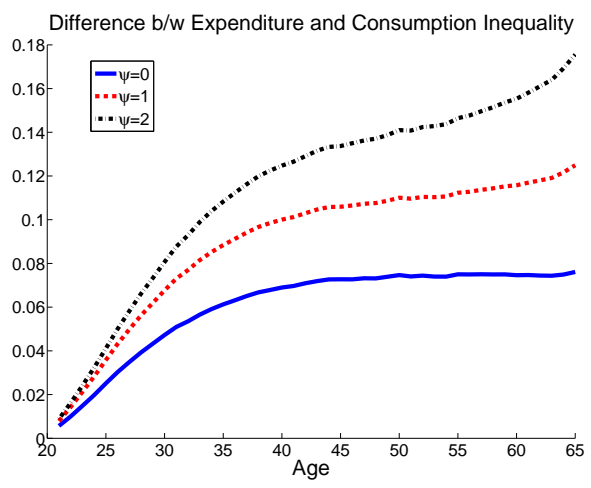

(a) Difference

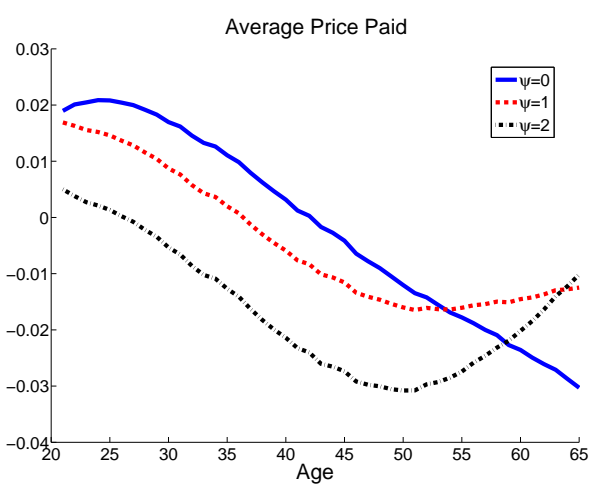

(b) Price Paid

Figure 16: The Effects of Time Cost of Search $(\psi)$ : These figures show the effects of $\psi$, a parameter governing time cost of price search, on the difference between variance of log expenditure and variance of log consumption (left panel), and on the average price paid over the life-cycle (right panel).

earlier studies, consumption inequality was implicitly assumed to be the same as expenditure inequality. ${ }^{24}$

Although we focused on age-inequality profiles, the model can be extended to explain further empirical observations. For instance, Aguiar and Hurst (2013) document different patterns in different expenditure categories. Price search can be helpful in explaining the different patterns because some categories may be more sensitive to price search than others. The life-cycle search profile may have different implications for the expenditure patterns of different categories due to their different sensitivities. Carroll and Summers (1989) document different expenditure patterns for different education groups. Again, price search together with conventional earning processes could be helpful in explaining these expenditure patterns. Different price search technologies or time cost profiles for different educational or occupational groups could be helpful in explaining the different expenditure patterns. In this paper, we used a fixed cost of time (the coefficient of leisure in the utility function) for the same age groups. It is possible that the variance of the opportunity cost of time across and within ages will vary over the life cycle for different educational and occupational groups. It may also have important implications for inequality in general.

\footnotetext{
${ }^{24}$ For example; Storesletten et al. (2004), Krueger and Perri (2006), and Guvenen (2007).
} 


\section{References}

[1] Aguiar, M. and M. Bils (forthcoming), "Has Consumption Inequality Mirrored Income Inequality?," American Ecnomic Review.

[2] Aguiar, M. and E. Hurst (2005), "Life Cycle Prices and Production," Boston Federal Reserve Bank Discussion Paper No: 05-3.

[3] Aguiar, M. and E. Hurst (2007), "Life-Cycle Prices and Production," American Economic Review, 97(5), 1533-1559.

[4] Aguiar, M. and E. Hurst (2013), "Deconstructing Life-Cycle Expenditure," Journal of Political Economy, 121(3), 437-492.

[5] Aiyagari, S. R. (1994), "Uninsured Idiosyncratic Risk and Aggregate Saving," The Quarterly Journal of Economics, 109(3), 659-84.

[6] Attanasio, O. P. and L. Pistaferri (2016), "Consumption Inequality," Journal of Economic Perspectives, 30(2), 3-28.

[7] Baye, M.R., J. Morgan and P. Scholten (2004), "Price Dispersion in the Small and in the Large: Evidence from an Internet Price Comparison Site," Journal of Industrial Economics, 52(4), 463496.

[8] Baye, M. R., J. Morgan, and P. Scholten (2006), "Information, Search, and Price Dispersion," Handbook on Economics and Information Systems.

[9] Becker, G. (1965), "A Theory of the Allocation of Time," The Economic Journal, 75, 493-517.

[10] Becker, G. and G. R Ghez (1975), "The Allocation of Time and Goods over the Life Cycle," NBER Working Paper.

[11] Blundell, R and I. Preston (1998), “Consumption Inequality and Income Uncertainty,? Quarterly Journal of Economics, 113 (2), 603-640.

[12] Blundell, R., L. Pistaferri, and I. Preston (2008), “Consumption Inequality and Partial Insurance," American Economic Review, 98(5), 1887-1921.

[13] Carroll, C. and L. Summers (1989), "Consumption Growth Parallels Income Growth: Some New Evidence," NBER Working Paper.

[14] Chang, Y. and S. Kim (2007), "Heterogeneity and Aggregation: Implications for LaborMarket Fluctuations," American Economic Review, 97(5), 1939-56. 
[15] Dahlbay B. and D. S. West (1986), "Price Dispersion in an Automobile Insurance Market," Journal of Political Economy, 94(2), 418-38.

[16] Deaton, A. and C. Paxson (1994), "Intertemporal Choice and Inequality," Journal of Political Economy, 102(3), 437-67.

[17] Gourinchas, P. and J. Parker (2002), “Consumption over the Life Cycle," Econometrica, 70(1), 47-89.

[18] Guner, N., G. Ventura and X. Yi (2008), "Macroeconomic Implications of Size-Dependent Policies," Review of Economic Dynamics, 11(4), 721-744.

[19] Guvenen, F. (2007), "Learning Your Earning, Are Labor Income Shocks Really Very Persistent?," American Economic Review, 97(3), 687-712.

[20] Guvenen, F. (2009), “An Empirical Investigation of Labor Income Processes," Review of Economic Dynamics, 12(1), 58-79.

[21] Heathcote, J., K. Storesletten and G. Violante (2010), “Unequal We Stand: An Empirical Analysis of Economic Inequality in the United States, 1967-2006, Review of Economic Dynamics, $13(1), 15-51$.

[22] Heathcote, J., K. Storesletten and G. Violante (2014), "Consumption and Labor Supply with Partial Insurance: An Analytical Framework," American Economic Review, 104(7), 2075-2126.

[23] Kaplan, G. (2012), “Inequality and the Lifecycle," Quantitative Economics, 3(3), 446-512.

[24] Kaplan, G. and G. Menzio (forthcoming), "Shopping Externalities and Self-Fulfilling Unemployment Fluctuations," Journal of Political Economy.

[25] Kaplan, G. and G. Menzio (2015), “The Morphology of Price Dispersion," International Economic Review, 56(4), 1165-1204.

[26] Kaplan, G. and G. Violante (2010), "How Much Consumption Insurance Beyond SelfInsurance?," American Economic Journal: Macroeconomics, 2(4), 53-87.

[27] Karahan, F. and S. Ozkan (2013), "On the Persistence of Income Shocks over the Life Cycle: Evidence and Implications," Review of Economic Dynamics, 16(3), 452-476.

[28] Krueger, D. and F. Perri (2006), "Does Income Inequality Lead to Consumption Inequality? Evidence and Theory," Review of Economic Studies, 73(1), 163-193.

[29] Li, Nicholas (2013), “An Engel Curve for Variety,” Working Paper 
[30] MaCurdy, T. E. (1982), "The Use of Time Series Processes to Model the Error Structure of Earnings in a Longitudinal Data Analysis," Journal of Econometrics, 18(1), 83-114.

[31] Pratt, J.W., D.A. Wise and R. Zeckhauser (1979), "Price Differences in Almost Competitive Markets," Quarterly Journal of Economics, 93(2), 189-211.

[32] Sorensen, A. (2000), "Equilibrium Price Dispersion in Retail Markets for Prescription Drugs," Journal of Political Economy, 108(4), 833-850.

[33] Stigler, G. J. (1961), “The Economics of Information,” Journal of Political Economy, 69(3), 213225.

[34] Storesletten, K., C. Telmer and A. Yaron (2004), "Consumption and Risk Sharing over the Life Cycle," Journal of Monetary Economics, 51(3), 609-633. 


\section{NOT FOR PUBLICATION Supplemental Appendix}

\section{Proofs}

Proof 1 [Lemma 1] When labor supply is positive, the FOCs with respect to price search and labor supply become

$$
\begin{aligned}
& s: \quad \alpha u_{2}=\lambda p^{\prime}(s) \\
& n: \quad u_{2}=-\lambda w c^{\psi-1}
\end{aligned}
$$

Combining these two equations results in

$$
p^{\prime}(s)=-\alpha w c^{\psi-1}
$$

If we take the total derivative of this equation with respect to $s$ and $y$, we arrive at

$$
p^{\prime \prime}(s) d s=-\alpha(\psi-1) w c^{\psi-2} \frac{d c}{d y} d y
$$

which can be written as

$$
\frac{d s}{d y}=-\alpha(\psi-1) \frac{w c^{\psi-2}}{p^{\prime \prime}(s)} \frac{d c}{d y}
$$

If consumption is normal good, then $\frac{d c}{d y}>0$, and if $p^{\prime \prime}(s)>0$, then the sign of $\frac{d s}{d y}$ is equal to the sign of $1-\psi$.

Proof 2 [Lemma 2] When labor supply is zero, $n=0$, the FOC to the individual's problem becomes

$$
c^{-\sigma}=\phi\left(1-\frac{1}{\theta_{1}}\right) \alpha s(\alpha s c)^{\gamma}
$$

and the budget constraint becomes $c=\frac{y}{p(s)}$. Substituting this into the above equation, we have

$$
\left(\frac{p(s)}{y}\right)^{\sigma+\gamma}=\phi\left(1-\frac{1}{\theta_{1}}\right)(\alpha s)^{1+\gamma}
$$

Taking the logs of both sides and using the equation for $p(s)$ we have

$$
\left[\theta_{1}(\sigma+\gamma)-(1+\gamma)\right] \log (s)=\log \left(\alpha^{1+\gamma} \phi\left(1-\frac{1}{\theta_{1}}\right)\right)-(\sigma+\gamma) \theta_{0}+(\sigma+\gamma) \log (y)
$$


Rearranging the terms results in

$$
\log (s)=\frac{\theta_{0}(\sigma+\gamma)-\log \left(\alpha^{1+\gamma} \phi\left(1-\frac{1}{\theta_{1}}\right)\right)}{(1+\gamma)-\theta_{1}(\sigma+\gamma)}-\frac{\sigma+\gamma}{(1+\gamma)-\theta_{1}(\sigma+\gamma)} \log (y)
$$

Proof 3 [Lemma 3] Expenditure is defined as

$$
\begin{aligned}
e & =p c \\
\log e & =\log p+\log c
\end{aligned}
$$

Substituting equation (5) into the above equation, we have

$$
\log e=\theta_{0}+\theta_{1} \log s+\log c
$$

Taking the variance of both sides, we get

$$
\operatorname{Var}(\log e)=\theta_{1}^{2} \operatorname{Var}(\log s)+\operatorname{Var}(\log c)+2 \theta_{1} \operatorname{Cov}(\log s, \log c)
$$

The FOC for price search evaluated at $n=0$ results in

$$
\log s=-\frac{\log \left(\phi \alpha^{1+\gamma}\left(1-\frac{1}{\theta_{1}}\right)\right)}{1+\gamma}-\frac{\sigma+\gamma}{1+\gamma} \log (c)
$$

Using this equation, we can write the $\operatorname{Var}(\log s)$ as

$$
\operatorname{Var}(\log s)=\left(\frac{\sigma+\gamma}{1+\gamma}\right)^{2} \operatorname{Var}(\log c)
$$

and Covar $(\log s, \log c)$ as

$$
\operatorname{Covar}(\log s, \log c)=-\frac{\sigma+\gamma}{1+\gamma} \operatorname{Var}(\log c)
$$

Substituting these expressions into (A1), we get

$$
\begin{aligned}
\operatorname{Var}(\log e) & =\left(\left(\theta_{1} \frac{\sigma+\gamma}{1+\gamma}\right)^{2}+1-2 \theta_{1} \frac{\sigma+\gamma}{1+\gamma}\right) \operatorname{Var}(\log c) \\
& =\left(1-\theta_{1} \frac{\sigma+\gamma}{1+\gamma}\right)^{2} \operatorname{Var}(\log c)
\end{aligned}
$$

Proof 4 [Lemma 4] When labor supply is positive, as expressed in equation (6), we have

$$
\log (s)=\frac{\theta_{0}+\log \left(\frac{-\theta_{1}}{\alpha}\right)}{1-\theta_{1}}-\frac{\log (w)}{1-\theta_{1}}
$$


Taking the variance of both sides, we arrive at

$$
\operatorname{Var}(\log s)=\left(\frac{1}{1-\theta_{1}}\right)^{2} \operatorname{Var}(\log w)
$$

Substituting this into $(A 1)$ we have

$$
\operatorname{Var}(\log e)=\left(\frac{\theta_{1}}{1-\theta_{1}}\right)^{2} \operatorname{Var}(\log w)+\operatorname{Var}(\log c)-2 \frac{\theta_{1}}{1-\theta_{1}} \operatorname{Cov}(\log c, \log w)
$$

Proof 5 [Lemma 5] The derivative of the price function with respect to search is $\frac{d p}{d s}=-s \int_{\underline{p}}^{\bar{p}} f(p)[1-F(p)]^{s-1} d p$. Since $f(p)>0$ for some $p<\bar{p}$, we have $\frac{d p}{d s}<0$. 